East African Medical Journal Vol. 81 No. 7 July 2004

PRIMARY THYROID LYMPHOMA: REPORT OF TWO CASES

Z. Akcali, MD., Medical Oncologist, H. Sakalli, MD., Fellow in Medical Oncology, T. Noyan, MD., Surgeon, F. Kayaselcuk, MD., Pathologist, O. Ozyilkan, MD., Medical Oncologist, Baskent University Faculty of Medicine 12. Sokar No. 7/3 Bahcelievler TR 06490, Ankara, Turkey

Request for reprints to: Dr. Z. Akcali, Division of Medical Oncology, Baskent University Faculty of Medicine 12. Sokar No. 7/3 Bahcelievler TR 06490, Ankara, Turkey

\title{
PRIMARY THYROID LYMPHOMA: REPORT OF TWO CASES
}

\author{
Z. AKCALI, H. SAKALLI, T. NOYAN, F. KAYASELCUK \\ and O. OZYILKAN
}

\begin{abstract}
SUMMARY
Primary thyroid Iymphoma is a rare disease. Most of the patients have a history of Hashimoto's thyroiditis. Main histopathologic subtypes are either mucosa-associated lymphoid tissue (MALT) or diffuse large cell lymphomas. Treatment options are surgical resection in localised, low-grade MALT lymphomas or systemic chemotherapy in aggressive, diffuse large cell lymphomas. But, sometimes other histopathologic subtypes can be seen and therapeutic approaches must be done. We report two patients who have primary thyroid lymphoma. There was no history of Hashimoto's thyroiditis in either case, and neither of them had MALT histologic subtype. First patient a sixty four year old woman, admitted to hospital because of bilateral thyroid nodules. Histological subtype was B cell follicular lymphoma. Subtotal thyroidectomy was performed and radiotherapy was administered to the entire neck region. Second patient, a 50 year old man, presented with complaints of a left thyroid mass and dyspnoea. Total thyroidectomy was carried out and chemotherapy was given. Histological diagnosis was diffuse large $B$ cell lymphoma. Thyroid lymphomas had heterogenous histological and clinical characteristics. In localised, non-aggressive subtypes, surgical treatment must be considered. Postoperative chemotherapy or radiotherapy may be necessary in some patients.
\end{abstract}

\section{INTRODUCTION}

Thyroid lymphoma is a rare form of thyroid malignancy that has heterogeneous histological and clinical characteristics. The thyroid gland does not contain native lymphoid tissues(1-3). The main subtypes of thyroid lymphoma are MALT in patients with autoimmune thyroiditis, and diffuse large B cell lymphoma. Almost all patients with these forms of thyroid lymphoma have a history of Hashimoto's thyroiditis. The five year survival rate for patients with thyroid lymphoma ranges from $10-35 \%$ in cases with unfavourable histology to $70 \%$ in those with favourable histology(4,5). Mediastinal involvement and performance status are important prognostic factors influencing relapse free survival and overall survival(6). Here we report two different thyroid lymphoma cases that were seen at our clinic in the past year. There was no history of Hashimoto's thyroiditis in either case.

\section{CASE REPORT}

Case I: A 64 year old woman presented to our hospital with bilateral thyroid masses. She had no history of thyroid disease and exhibited no B symptoms of lymphoma. Physical examination revealed a $3 \times 2 \times 2 \mathrm{~cm}$ nodule in each of the thyroid lobes. There was no associated pain, and the patient did not exhibit dysphagia, dyspnoea, peripheral lymphadenopathy, or splenomegaly. A peripheral blood smear showed hypochromic microcytic anaemia; however, this was not surprising because thalassaemia intermedia had been diagnosed previously. Laboratory studies revealed that the patient's erythrocyte sedimentation rate and serum levels of lactate dehydrogenase (LHD), $\beta_{2}$ microglobulin, thyroid-stimulating hormone (TSH), anti-thyroglobulin (anti-T) anticore and anti-microsomal (anti-M) anticore were all within normal limits. An ultrasound examination of the thyroid gland revealed one nodule in each lobe, with the largest measuring $27 \times 25 \times 30 \mathrm{~mm}$. Fine-needle biopsy of the right thyroid nodule showed lymphoid cell infiltration. Computed tomography demonstrated bilateral nodules and diffuse infiltration in thyroid gland (Figure 1) and tiny lymph nodules in the patient's thorax. Subtotal thyroidectomy was performed and the histopathologic diagnosis was B cell follicular lymphoma (Figure 2). There was no involvement of the lymph nodes or bone marrow, and the disease was classified as stage IE. Adjuvant 5600 cGY radiotherapy was administered to the patient's entire neck region. At the time of writing, our patient had been followed up for 16 months without relapse. Tiny lymph nodules in the thorax had remained, so they are assumed as benign nodules. 
Case 2: A 50 year old male patient presented with complaints of a left thyroid mass and shortness of breath. He had first noted both problems two months earlier. On admission, the patient's temperature, respiratory rate, and haemodynamic parameters were all within normal limits.

\section{Figure 1}

CT: Hypodensity due to diffuse infiltration in both lobes and the isthmus of the thyroid gland

\section{Figure 3}

MRI: Hypodensity due to lymphoma infiltration in both lobes of the thyroid gland and a cystic lesion in isthmus

Figure 4

CD 20 positive, atypical lymphoid infiltration (IHC X 200)

Figure 2

The haematological profile, biochemical analysis, erythrocyte sedimentation rate, and serum levels of $\beta_{2}$ microglobulin and TSH were also normal. His anti-T anticore level was $66.7 \mathrm{IU} / \mathrm{ml}$ (normal limits: 0-40 IU/ $\mathrm{ml}$ ), and his anti-M anticore level was $37 \mathrm{IU} / \mathrm{ml}$ (normal limits 0-50) IU/ml). Magnetic resonance imaging of the neck revealed a $6 \times 4-\mathrm{cm}$ mass and diffuse infiltration in thyroid gland and multiple lymphadenopathy on the left side of the neck (Figure 3). Total thyroidectomy was carried out, and the histopathologic diagnosis was diffuse large B cell lymphoma (Figure 4). There was no bone marrow infiltration, and the disease was classified as stage IIE. Six cycles of CHOP chemotherapy were given. At the time of writing, the patient had been in remission for 12 months after thyroidectomy 


\section{DISCUSSION}

Malignancies of the thyroid gland have elicited far more concern than their incidence might suggest. Primary lymphoma of the thyroid gland is being reported with increased frequency(6). Generally, these cases present with a rapidly enlarging thyroid mass(7). Both of our patients' initial complaints were masses in the thyroid gland. Most cases of thyroid lymphoma arise in individuals who have a history of Hashimoto's thyroiditis, and most are of MALT origin. The presence of anti-thyroid antibodies indicates immune thyroiditis, and may suggest a benign aetiology for the thyroid nodule. However both differentiated thyroid carcinoma and thyroid lymphomas may be associated with Hashimoto's disease, so the presence of anti-thyroid antibodies in no way rules out malignancy. In our first case, the anti-thyroid antibody levels were within normal limits, but the second patient had a slightly elevated anti-T anticore level. There was no history of Hashimoto's thyroiditis in either case, and neither of the tumours were MALT histologic subtype.

The clinical presentation of thyroid lymphoma is categorised as aggressive or favourable. Most patients with diffuse large cell lymphoma present with poor performance status. B symptoms, and high serum LDH and $\beta_{2}$, microglobulin levels. Although polychemotherapy regimens are used in these cases, the prognosis is still poor. In contrast, the prognosis is favourable for cases of MALT lymphoma, which account for $25 \%$ of all thyroid lymphomas. In these patients, the disease is often localized to the thyroid tissue, and the preferred treatment is total thyroidectomy and/or involved-field radiation therapy. As with other forms of lymphoma, the choice of treatment for thyroid lymphoma depends on histological subtype and stage of disease. Since our patients both had localized disease, primary surgical treatment was the most appropriate approach. Postoperative radiotherapy was applied in Case 1 but chemotherapy was administered in Case 2 because the patient's cervical lymph nodes were involved, and histologic subtype was diffuse large B cell lymphoma.

In summary, these two unusual cases of thyroid lymphoma are of particular interest because there was no history of Hashimoto's thyroiditis in either case, and neither tumour was MALT subtype.

\section{REFERENCES}

1. Thieblemont, C., Mayer, A. Dumontet, C., et al. Primary thyroid lymphoma is a heterogeneous disease. J. Clin. Endocrinol. Metab. 2002; 87:105-111.

2. Pedersen, R. K. and Pedersen, N. T. Primary non-Hodgkin's lymphoma of the thyroid gland: a population-based study. Histopathology 1996; 28:25-32.

3. Anscombe, A. M. and Wright D. H. Primary malignant lymphoma of the thyroid -a tumour of mucosa-associated lymphoid tissue: review of seventy-six cases. Histopathology 1985; 9:81-97.

4. Skarsgard, E. D., Connors, J. M. and Robins, R. E. A current analysis of primary lymphoma of the thyroid. Arch. Surg. 1991; 126:1199-1203.

5. Pledge, S., Bessell, E. M., Leach, I. H., et al. Non-Hodgkin's lymphoma of the thyroid: a retrospective review of all patients diagnosed in Nottinghamshire from 1973 to 1992. Clin. Oncol. 1996, 8:371-375.

6. Belal, A. A., Allam, A.. Kandil, A., et al. A primary thyroid lymphoma: a retrospective analysis of prognostic factors and treatment outcome for localized intermediate and high grade lymphoma. Am. J. Clin. Oncol. 2001; 24:299-305.

7. Paccalin, M., Gouet, D., Ribouleau, V., et al. Primary thyroid lymphoma: report of 8 cases. Rev. Med. Intern. 2001; 22:934-938. 